\title{
Malignant Narcissism: Concealed Side of Psychopathy
}

\author{
Saeed Shoja Shafti * \\ Professor of Psychiatry, University of Social Welfare and Rehabilitation Sciences, Razi Psychiatric Hospital, Iran
}

*Corresponding author: Saeed Shoja Shafti, Professor of Psychiatry, University of Social Welfare and Rehabilitation Sciences, Razi Psychiatric Hospital, IranProfessor of Psychiatry, University of Social Welfare and Rehabilitation Sciences, Razi Psychiatric Hospital, Iran

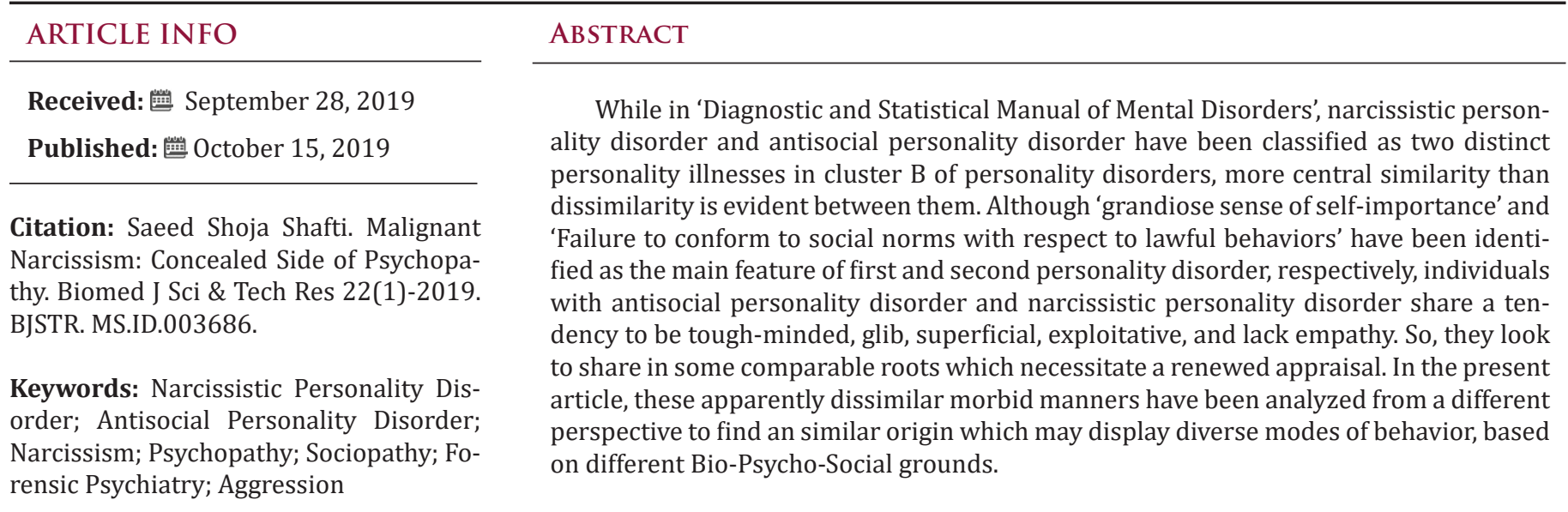

\section{Introduction}

The essential feature of Narcissistic Personality Disorder (NPD) is a pervasive pattern of grandiosity, need for admiration, and lack of empathy that begins by early adulthood and is present in a variety of contexts. Individuals with this disorder have a grandiose sense of self-importance [1] (Table 1). They routinely overestimate their abilities and inflate their accomplishments, often appearing boastful and pretentious. Often implicit in the inflated judgments of their own accomplishments is an underestimation (devaluation) of the contributions of others. They may feel that they can only be understood by, and should only associate with, other people who are special or of high status and may attribute "unique," "perfect," or "gifted" qualities to those with whom they associate. Individuals with this disorder believe that their needs are special and beyond the ken of ordinary people. Their own self-esteem is enhanced (i.e., "mirrored") by the idealized value that they assign to those with whom they associate. While individuals with this disorder generally require excessive admiration, their self-esteem is almost invariably very fragile. A sense of entitlement, combined with a lack of sensitivity to the wants and needs of others, may result in the conscious or unwitting exploitation of others [1]. Individuals with narcissistic personality disorder generally have a lack of empathy and have difficulty recognizing the desires, subjective experiences, and feelings of others. They tend to discuss their own concerns in inappropriate and lengthy detail, while failing to recognize that others also have feelings and needs. They are often contemptuous and impatient with others who talk about their own problems and concerns. These individuals may be oblivious to the hurt their remarks may inflict. These individuals are often envious of others or believe that others are envious of them. Arrogant, haughty behaviors characterize these individuals. On the other hand, vulnerability in self-esteem makes individuals with narcissistic personality disorder very sensitive to "injury" from criticism or defeat. They may react with disdain, rage, or defiant counterattack [1].

Such experiences often lead to social withdrawal or an appearance of humility that may mask and protect the grandiosity. Sustained feelings of shame or humiliation and the attendant self-criticism may be associated with social withdrawal, depressed mood, and persistent depressive disorder (dysthymia) or major depressive disorder. In contrast, sustained periods of grandiosity may be associated with a hypomanie mood. Narcissistic personality disorder is also associated with anorexia nervosa and substance use 
disorders (especially related to cocaine) [2]. Histrionic, borderline, antisocial, and paranoid personality disorders may be associated with narcissistic personality disorder [1].

On the other hand, the essential feature of antisocial personality disorder (APD) is a pervasive pattern of disregard for, and violation of, the rights of others that begins in childhood or early adolescence and continues into adulthood. This pattern has also been referred to as psychopathy, sociopathy, or dyssocial personality disorder. Individuals with antisocial personality disorder fail to conform to social norms with respect to lawful behavior [3]. They may repeatedly perform acts that are grounds for arrest (whether they are arrested or not), such as destroying property, harassing others, stealing, or pursuing illegal occupations. Persons with this disorder disregard the wishes, rights, or feelings of others. They are frequently deceitful and manipulative in order to gain personal profit or pleasure. They may repeatedly lie, use an alias, con others, or malinger [3]. A pattern of impulsivity may be manifested by a failure to plan ahead. Individuals with antisocial personality disorder tend to be irritable and aggressive and may repeatedly get into physical fights or commit acts of physical assault. These individuals also display a reckless disregard for the safety of themselves or others.

Table 1: Diagnostic criteria of narcissistic and antisocial personality disorders, plus there, relatively, common features.
They may engage in sexual behavior or substance use that has a high risk for harmful consequences. Individuals with antisocial personality disorder also tend to be consistently and extremely irresponsible, including financial irresponsibility and show little remorse for the consequences of their acts. Psychopaths frequently lack empathy and tend to be callous, cynical, and contemptuous of the feelings, rights, and sufferings of others. They may have an inflated and arrogant self-appraisal and may be excessively opinionated, self-assured, or cocky. Lack of empathy, inflated self-appraisal, and superficial charm are features that have been commonly included in traditional conceptions of psychopathy that may be particularly distinguishing of the disorder [3]. These individuals are more likely than people in the general population to die prematurely by violent means (e.g., suicide, accidents, and homicides). Individuals with antisocial personality disorder may also experience dysphoria, including complaints of tension, inability to tolerate boredom, and depressed mood. They may have associated anxiety disorders, depressive disorders, substance use disorders, somatic symptom disorder, gambling disorder, and other disorders of impulse control [3]. Individuals with antisocial personality disorder also often have personality features that meet criteria for other personality disorders, particularly borderline, histrionic, and narcissistic personality disorders [3] (Table 1).

\begin{tabular}{|c|c|c|c|}
\hline Criteria & Antisocial Personality Disorder $(\geq 3)$ & Diagnostic Criteria of Narcissistic Personality Disorder $(\geq 5)$ & Overall Shared Features \\
\hline 1 & $\begin{array}{l}\text { Failure to conform to social norms with } \\
\text { respect to lawful behaviors, as indicated by } \\
\text { repeatedly performing acts that are grounds } \\
\text { for arrest. }\end{array}$ & $\begin{array}{l}\text { Has a grandiose sense of self-importance (e.g., exaggerates } \\
\text { achievements and talents, expects to be recognized as superior } \\
\text { without commensurate achievements). }\end{array}$ & Criminality \\
\hline 2 & $\begin{array}{l}\text { Deceitfulness, as indicated by repeated } \\
\text { lying, use of aliases, or conning others for } \\
\text { personal profit or pleasure. }\end{array}$ & $\begin{array}{l}\text { Is preoccupied with fantasies of unlimited success, power, } \\
\text { brilliance, beauty, or ideal love. }\end{array}$ & Lying \\
\hline 3 & Impulsivity or failure to plan ahead & $\begin{array}{c}\text { Believes that he or she is "special" and unique and can only be } \\
\text { understood by, or should associate with, other special or high- } \\
\text { status people (or institutions }\end{array}$ & Selfishness \\
\hline 4 & $\begin{array}{l}\text { Irritability and aggressiveness, as indicated } \\
\text { by repeated physical fights or assaults. }\end{array}$ & Requires excessive admiration & Aggressiveness \\
\hline 5 & $\begin{array}{l}\text { Reckless disregard for safety of self or } \\
\text { others. }\end{array}$ & $\begin{array}{l}\text { Has a sense of entitlement (i.e., unreasonable expectations of } \\
\text { especially favorable treatment or automatic compliance with his } \\
\text { or her expectations). }\end{array}$ & Abusiveness \\
\hline 6 & $\begin{array}{l}\text { Consistent irresponsibility, as indicated by } \\
\text { repeated failure to sustain consistent work } \\
\text { behavior or honor financial obligations. }\end{array}$ & $\begin{array}{l}\text { Is interpersonally exploitative (i.e., takes advantage of others to } \\
\text { achieve his or her own ends). }\end{array}$ & Exploitation \\
\hline 7 & $\begin{array}{l}\text { Lack of remorse, as indicated by being } \\
\text { indifferent to or rationalizing having hurt, } \\
\text { mistreated, or stolen from another. }\end{array}$ & $\begin{array}{l}\text { Lacks empathy is unwilling to recognize or identify with the } \\
\text { feelings and needs of others. }\end{array}$ & Cruelty \\
\hline 8 & - & $\begin{array}{l}\text { Is often envious of others or believes that others are envious of } \\
\text { him or her. }\end{array}$ & Suspiciousness \\
\hline 9 & - & Shows arrogant, haughty behaviors or attitudes & Overconfidence \\
\hline
\end{tabular}

\section{Differential Diagnosis}

The most useful feature in discriminating narcissistic personality disorder from histrionic, antisocial, and borderline personality disorders, in which the interactive styles are coquettish, callous, and needy, respectively, is the grandiosity characteristic of narcissistic personality disorder [3]. In general, individuals with antisocial personality disorder and narcissistic personality disorder share a tendency to be tough-minded, glib, superficial, exploitative, 
and lack empathy. However, according to DSM-5, narcissistic personality disorder does not include characteristics of impulsivity, aggression, and deceit. In addition, individuals with antisocial personality disorder may not be as needy of the admiration and envy of others, and persons with narcissistic personality disorder usually lack the history of conduct disorder in childhood or criminal behavior in adulthood [3]. Antisocial personality disorder, the current official term for psychopathy, was the first personality disorder to be officially recognized within psychiatry and to be included in the earliest version of the American Psychiatric Association's Diagnostic and Statistical Manual of Mental Disorders, known to all mental health practitioners as DSM [4].

DSM-II, published in 1968, changed the term psychopath to sociopath, and more clearly refined it. DSM-IV, published in 1994 with text revisions in 2000 (DSM-IV-TR), emphasizes antisocial behavior, more than personality traits and their motivation, in the definition of antisocial personality disorder. This version of DSM stresses predisposing childhood factors, such as attention-deficit/ hyperactivity disorder and conduct disorder. It also emphasizes criminal behavior over the essential narcissistic features of the disorder [4].

\section{Interrelationship}

According to akhtar, while overtly, and individual with narcissistic personality disorder is grandiose, exploitative, moralistic, often successful, seductive, charming, and impressively knowledgeable and articulate, Covertly, however, he is doubt ridden, deeply envious of others, chronically bored, corruptible, unable to love, forgetful of details, and inattentive to objective aspects of events [5]. There are three main aspects of narcissism:

a) Narcissism as a psychological construct in the sense of personality variable,

b) As a factor of vulnerability for other psychological disorders and

c) As a personality disorder (NPD).

While there are no clear boundaries between these forms of narcissism, The NPD is recognized as a personality disorder by DSM-IV but not by ICD-10. On the other hand, there is a clear lack of scientific studies on the neurobiology, psychology and psychotherapeutic as well as psychopharmacological treatment [6]. Despite converging support for two phenotypic themes associated with pathological narcissism, psychiatric diagnosis and social/personality psychology research often focus only on grandiosity in the assessment of narcissism [7]. On the other side, Kernberg believes that persons with antisocial personality disorder are basically suffering from a severe type of narcissistic personality disorder [8]. They form only exploitative relationships and lack moral principle. Roughly defined, the psychiatric concept of narcissism refers to a person's sense of self-importance and uniqueness. Narcissism may be healthy or pathological. In the psychopath, it is pathological in the extreme and is malignantly transformed into living, breathing evil [8].

As noted above, the psychopath typically manifests pathological self-importance, or narcissism, displayed as excessive selfcenteredness. Other characteristic traits are grandiosity (displayed as nonsexual exhibitionism), recklessness, over-ambitiousness, an attitude of superiority, over-dependency on admiration, and, alternating with these characteristics, bouts of insecurity and emotional shallowness [9]. But not all criminals are psychopaths; in fact, many are not. And not all psychopaths are criminals; in fact, again, many are not. Psychopaths exist at all levels of society, in all walks of life [10]. Psychopaths can be passive or aggressive. Passive psychopaths tend to be parasitic and exploitative of others, whereas aggressive psychopaths commit major crimes [9]. Passive psychopaths (referred to as passive-parasitic, exploitative, or predatory) have frequent scrapes with the law but usually manage to squirm out of serious trouble and punishment.

Passive psychopaths commit mostly white-collar crimes. For the most part, however, the average, everyday psychopath among us (and within us) appears to the outside world as a model of normality [10]. Hitherto, little research has examined different dimensions of narcissism that may parallel psychopathy facets in criminally involved individuals. In a study for assessment of relationships between grandiose and vulnerable narcissism, and the four facets of psychopathy (interpersonal, affective, lifestyle, and antisocial), grandiose and vulnerable narcissism showed differential relationships to psychopathy facets, with grandiose narcissism relating positively to the interpersonal facet of psychopathy and vulnerable narcissism relating positively to the lifestyle facet of psychopathy. Also, while vulnerable narcissism showed stronger associations than grandiose narcissism to

a) Other forms of psychopathology, including internalizing and substance use disorders, and

b) Self- and other-directed aggression

Grandiose narcissism was nonetheless associated with social dysfunction marked by a manipulative and deceitful interpersonal style and unprovoked aggression [11]. In this regard, current conceptualizations of and research regarding narcissism, nonetheless, suggest that not all individuals with narcissism solely display a grandiose sense of self. Rather, there seems to be two fairly distinct dimensions of narcissism: grandiose and vulnerable narcissism [12]. Grandiose narcissism refers to the openly arrogant and superior presentation, whereas vulnerable narcissism is characterized by conflict between a grandiose and an inferior sense of self [13]. Thus, individuals high on grandiose narcissism are poised, self-confident, and exhibitionistic [12]. In contrast, those scoring high on vulnerable narcissism can be exploitative and entitled, but the hallmark symptoms involve hypersensitivity to criticism, fear of rejection, and a fragile self-esteem [14]. Both narcissism dimensions are currently embedded in narcissistic personality disorder (NPD) as a 
single syndrome [1]. Most studies that have been conducted on narcissism is relatively limited in scope in that they have relied mostly on samples without severe functional impairments and measures of narcissism that mostly assess grandiose traits [15]. Narcissism and psychopathy have been linked in the literature already, as evidenced by research on the "dark triad" (i.e. narcissism, psychopathy, and Machiavellianism [16].

In addition, psychopathy has been designated as a theoretic framework for examining narcissism in an externalizing sample due to symptom overlap among the disorders and their respective associations with heightened risk for aggression and engagement in illegal behavior $[17,18]$. There is both conceptual and empirical overlap among narcissism and psychopathy in forensic samples, suggesting these disorders may share underlying vulnerabilities for personality pathology $[19,20]$. Further, narcissism and psychopathy converge at the trait-level of personality in that both disorders are marked by grandiosity, manipulativeness, and callousness and with the five-factor model dimensions of low agreeableness and high extraversion [21]. Study has shown that narcissistic traits may also increase risk for aggression [22,23], and theory suggests that aggressive tendencies influence the degree to which narcissism is pathological [24]. For instance, Bushman et al. provide evidence that the grandiose features of narcissism can promote aggression, especially when an individual's self-esteem is threatened [25].

There is very limited empirical evidence on the relationship between vulnerable narcissism and aggression, but preliminary data indicates that vulnerable narcissism is associated with homicidal ideation as well as self-directed violence, including suicide attempts [26]. Vulnerable narcissism, in general, seems to be marked by high levels of disinhibition [27].

\section{Narcissism and Criminal Behavior}

Criminal behavior, or adult antisocial behavior, as it is referred to by psychiatrists, encompasses a wide spectrum of conduct and describes normally functioning people engaged in making a dishonest living, perhaps out of necessity; those who are driven to criminal behavior out of guilt in order to be caught and punished; and those who are brain damaged, either by birth or by drugs. Narcotics, alcohol, and other drugs that strongly affect the brain are contributing more and more to the rising tide of antisocial behavior [28]. As said above, not all criminals are psychopaths; in fact, many are not [10]. So, other traits, as well, may be noted with respect to forensic issues. Among a variety of characters, narcissism has absorbed publicly loads of attention [29,30]. In this regard, malignant narcissism is known as a mixture of narcissism and antisocial personality disorder. As well as having symptoms of a Narcissistic Personality Disorder, a person with malignant narcissism also displays paranoia. Since the personality of a malignant narcissist cannot tolerate any criticism, paranoia is usually stemmed from being mocked. For example, according to Diamond, there is a close correlation between antisocial behavior and pathological narcissism. So, he employed the term 'psychopathic narcissism' to describe such individuals." [31] Narcissists are great manipulators. They can spot the needs, emotions, and weaknesses in those around them and use this information to their advantage very quickly with no sense of regret. They do not have a conscience in this sense because they do not hold themselves responsible for the consequences of their actions; they simply worked with the information that was available [32]. Narcissists do not admit they have any faults or could be at fault because they genuinely don't believe that they are. They would not call themselves a narcissist and they certainly wouldn't believe that they had a personality disorder [33]. Narcissistic rage is a psychological construct that describes a reaction to narcissistic injury, which is conceptualized as a perceived threat to a narcissist's self-esteem or self-worth. The term narcissistic rage was coined by Heinz Kohut in 1972.

Narcissistic rage occurs on a continuum, which may range from instances of aloofness and expressions of mild irritation or annoyance to serious outbursts, including violent attacks and murder [34]. For Kohut, narcissistic rage is related to narcissists' need for total control of their environment, including "the need for revenge, for righting a wrong, for undoing a hurt by whatever means". It is an attempt by the narcissist to turn from a passive sense of victimization to an active role in giving pain to others, while at the same time attempting to rebuild their own (actually false) sense of self-worth. It may also involve self-protection and preservation, with rage serving to restore a sense of safety and power by destroying that which had threatened the narcissist [35]. Alternatively, according to Kohut, rages can be seen as a result of the shame at being faced with failure. Narcissistic rage is the uncontrollable and unexpected anger that results from a narcissistic injury - a threat to a narcissist's self-esteem or worth.

Rage comes in many forms, but all pertain to the same important thing: revenge. Narcissistic rages are based on fear and will endure even after the threat is gone [36]. To the narcissist, the rage is directed towards the person that they feel has slighted them; to other people, the rage is incoherent and unjust. This rage impairs their cognition, therefore impairing their judgment. During the rage they are prone to shouting, fact distortion and making groundless accusations [36]. In his book The Analysis of the Self, Kohut explains that expressions caused by a sense of things not going the expected way blossom into rages, and narcissists may even search for conflict to find a way to alleviate their pain or suffering. He also noted how psychoanalytic treatment might itself be experienced by a patient as an unbearable narcissistic injury [36]. In another article focusing on mass shootings and a possible link of narcissistic rage between different cases, Chung discusses the work of Kohut in light of the various mass shootings which have taken place in America [37].

Comparing such cases brings some interesting points where narcissistic behaviors and a lack of empathy can clearly be seen. A common theme among such tragic events can be the impression 
that such actions will bring narcissists notoriety and magnificence, which they are worthy of. Grandiosity, uniqueness, and lack of empathy were the specific qualities which have featured their temperament. Furthermore, the idea of retaliation against those they feel have done them wrong, as well, looks to be a trend in mass shootings [37]. Another explanation as well can be supposed with respect to narcissist's negative profile of behavior and rage. As is known in the realm of forensic psychiatry, in 'Schizophrenia Spectrum and Other Psychotic Disorders', delusional disorder is the most dangerous one with respect to probability of aggressiveness, inflicting injury and even murdering the alleged target. The difference between overvalued idea, which is usually acknowledged as the main psychopathologic structure of malignant narcissism, and delusion, while supposedly seems easy, is not always practical, because the overvalued idea, as like as surroundings or mood, may organize the thoughts for falling into secondary delusions. So, a mutual connection between malignant narcissism and grandiose type of delusional disorder is supposable, which is many times deductible based on sequence of events. Some studies are available which have talked over similar circumstances [38].

\section{Conclusion}

It seems that similarity between the core structure of primary sociopathy and morbid narcissism is more than a minor overlap. When there is no cutting-edge code regarding truthfulness, faithfulness and empathy in interpersonal relationship, hence there is no pause or averseness as regards consideration of people's feelings and profits. Such a person cannot be acknowledged as a considerate person that evaluate the surrounds by a suitable sense of judgment or conscience, and so, may allow himself or herself to do everything for subjective profits or desires. Twofaced attitude of narcissist, which is usually less applicable to sociopaths, may make this similarity blurrier. Accordingly, while external behavior of these two lifestyles seems poles apart due to various reasons, the essence of social judgement and manner is based on an identical deficit, which may be indicated as lack or shortfall of superego. Disregard to the likelihood of presence of delusion as the core structure of malignant narcissism, if classification could be accomplished based on morals or principles, instead of merely descriptive or phenomenological psychopathology, the morbid narcissism, as well, could be regarded as the covert feature of a construction, which comprises primary sociopathy as its overt aspect.

\section{References}

1. (2013) American Psychiatric Association (APA). Diagnostic and Statistical Manual of Mental Disorders. (5 $5^{\text {th }}$ edn.). American Psychiatric Association, Washington, DC 2013: 669-672.

2. Ronningstam E (1996) Pathological narcissism and narcissistic personality disorder in Axis I disorders. Harv Rev Psychiatry 3(6): 326340.

3. (2013) American Psychiatric Association (APA). Diagnostic and Statistical Manual of Mental Disorders. (5 $5^{\text {th }}$ edn.) American Psychiatric Association, Washington, DC 2013: 6593-6663.
4. Robert I Simon (2008) Bad Men Do What Good Men Dream: A Forensic Psychiatrist Illuminates the Darker Side of Human Behavior. American Psychiatric Publishing, Inc. Washington DC, USA, p. 29-53.

5. Akhtar S (1989) Narcissistic personality disorder. Descriptive features and differential diagnosis. Psychiatr Clin North Am 12(3): 505-529.

6. Ritter K, Lammers CH (2007) Narcissism--variable of personality and personality disorder. Psychother Psychosom Med Psychol 57(2): 53-60.

7. Cain NM, Pincus AL, Ansell EB (2008) Narcissism at the crossroads: phenotypic description of pathological narcissism across clinical theory, social/personality psychology and psychiatric diagnosis. Clin Psychol Rev 28(4): 638-656.

8. Kernberg OF (1992) Aggression in Personality Disorders and Perversions. New Haven, CT, Yale University Press pp. 67-84.

9. Reid WH (1994) Antisocial personality in forensic psychiatry, in Principles and Practice of Forensic Psychiatry. In Rosner R(Eds), (2 $2^{\text {nd }}$ Edn.). Chapman \& Hall, New York, USA, pp: 427-431.

10. Skodol AE, Gunderson JG (2008) Personality disorders, in American Psychiatric Publishing Textbook of Psychiatry. In: Hales RE, Yudofsky SC, Gabbard GO (Eds.), (5 $5^{\text {th }}$ edn.). American Psychiatric Publishing, Washington DC, USA, pp: 821-860.

11. (2011) NIH-PA Author Manuscript. Parallel Syndromes: Two Dimensions of Narcissism and the Facets of Psychopathic Personality in Criminally Involved Individuals. Personal Disord 2(2): 113-127.

12. Wink P (1991) Two faces of narcissism. Journal of Personality and Social Psychology 61(4): 590-597.

13. Kernberg OF (1975) Borderline conditions and pathological narcissism. Jason Aronson, New York, USA.

14. Akhtar S, Thomson JA (1982) Overview: Narcissistic personality disorder. The American Journal of Psychiatry 139(1): 12-20.

15. Pincus AL, Ansell EB, Pimentel CA, Cain NM, Wright AGC, et al. (2009) Initial construction and validation of the Pathological Narcissism Inventory. Psychological Assessment 21(3): 365-379.

16. Paulhus DL, Williams KM (2002) The Dark Triad of personality: Narcissism, Machiavellianism, and psychopathy. Journal of Research in Personality 36(6): 556-563.

17. Hare RD (2003) Psychopathy Checklist-Revised. In: Hare RD (Eds.), (2 ${ }^{\text {nd }}$ edn.). Multi-Health Systems; Toronto, Canada.

18. Jones DN, Paulhus DL (2010) Different provocations trigger aggression in narcissists and psychopaths. Social Psychological and Personality Science 1(1): 12-18.

19. Bushman BJ, Baumeister RF (1998) Threatened egotism, narcissism, self-esteem and direct and displaced aggression: Does self-love or selfhate lead to violence? Journal of Personality and Social Psychology 75(1): 219-229.

20. Cleckley H (1976) The mask of sanity. In: Cleckley H (Ed.), (5 ${ }^{\text {th }}$ edn.), St. Louis, Mosby, USA 1976.

21. Samuel DB, Widiger TA (2008) Convergence of narcissism measures from the perspective of general personality functioning. Assessment 15(3): 364-374.

22. Jones DN, Paulhus DL (2010) Different provocations trigger aggression in narcissists and psychopaths. Social Psychological and Personality Science 1(1): 12-18.

23. Paulhus DL, Robins RW, Trzesniewski KH, Tracy JL (2004) Two replicable suppressor situations in personality research. Multivariate Behavioral Research 39(2): 303-328.

24. Kernberg OF, Caligor E (2005) A psychoanalytic theory of personality disorders. In Lenzenweger MF, Clarkin JF (Eds.), (2 ${ }^{\text {nd }}$ Edn.). Major theories of personality disorder. Guilford Press, New York, USA, pp: 14156. 
25. Bushman BJ, Baumeister RF, Thomaes S, Ryu E, Begeer S (2009) Looking again, and harder, for a link between low self-esteem and aggression. Journal of Personality 77(2): 427-446.

26. Pincus AL, Ansell EB, Pimentel CA, Cain NM, Wright AGC (2009) Initial construction and validation of the Pathological Narcissism Inventory. Psychological Assessment 21(3): 365-379.

27. Hill CD, Neumann CS, Rogers R (2004) Confirmatory factor analysis of the Psychopathy Checklist: Screening Version in offenders with Axis I disorders. Psychological Assessment 16(1): 90-95.

28. Dinitz S. The Antisocial Personality in Forensic Psychiatry and Psychology.

29. Curran WJ, McGarry AL, Shah SA (1986) Narcissistic Behaviour and The Human Ego. In Curran WJ, McGarry AL, Shah SA (Eds.), FA Davis, Philadelphia, PA, pp. 391-408.

30. https://www.crimetraveller.org/2015/07/narcissistic-rage-coldblooded-murder/

31. Diamond SA (2012) Joran, Casey and Psychopathic Narcissism: A Forensic Commentary. Evil Deeds Blog. Psychology Today.

\section{ISSN: 2574-1241}

DOI: 10.26717/BJSTR.2019.22.003686

Saeed Shoja Shafti. Biomed J Sci \& Tech Res

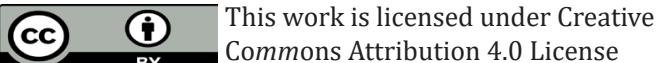

Submission Link: https://biomedres.us/submit-manuscript.php
32. Ronningstam E (2011) Narcissistic Personality Disorder in DSM-VIn Support of Retaining a Significant Diagnosis. Journal of Personality Disorders 25(2): 248-259.

33. Akhtar S (2009) Comprehensive Dictionary of Psychoanalysis. In: Akhtar S (Ed.), Karnac Books, London, England, pp. 182.

34. Malmquist CP (2006) Homicide: A Psychiatric Perspective. In Malmquist CP (Eds.), American Psychiatric Publishing, Washington DC, USA, pp. 181-182.

35. Ronningstam E (2005) Identifying and understanding the narcissistic personality. Oxford University, Oxford, England pp. 86-87.

36. Kohut H (1972) Thoughts on narcissism and narcissistic rage. In: The search for the self. Madison, Connecticut: International Universities Press pp. 615-658.

37. Chung W (2014) Killers in mass shootings linked by narcissistic rage.

38. Subramanian K, Selvakumar N, Karunanithi A, Rajan TM, Kandasamy P (2018) Quasi-psychosis in covert Narcissistic Personality Disorder-A case report. Asian J Psychiatr 32: 143-144.

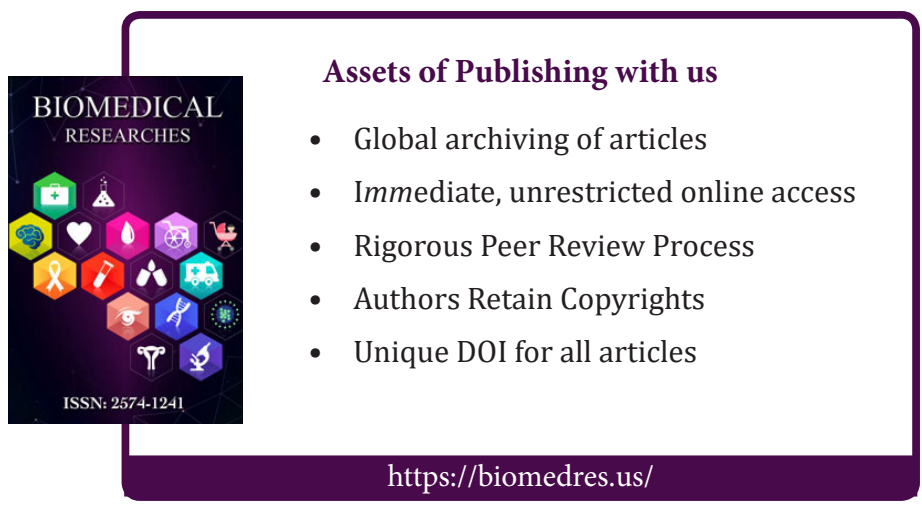

